\title{
Enraizamento de miniestacas herbáceas de maracujazeiro amarelo
}

\section{Rooting of herbaceous minicuttings of passion fruit}

\author{
Ruy Inacio Neiva de Carvalho ${ }^{1 *}$; Ivo Ditos da Silva²; Rudival Faquim ${ }^{2}$
}

\section{Resumo}

Este trabalho objetivou avaliar a influência do corte basal, da presença da folha e do tratamento com suspensão de raízes no enraizamento de miniestacas herbáceas de maracujazeiro amarelo. O experimento foi conduzido em casa de vegetação com miniestacas de $8 \mathrm{~cm}$ de comprimento e dois nós, obtidas de mudas de maracujazeiro. O corte longitudinal na base das estacas foi feito até o nó basal. Foram retiradas as folhas ou mantida a metade da folha do nó apical. As miniestacas foram tratadas com suspensão de raízes mais água nas concentrações de 0,100 e $200 \mathrm{~g} \mathrm{~L}^{-1}$. Após 58 dias, determinou-se a porcentagem de estacas enraizadas, o número de raízes emitidas e a massa seca de raízes por estaca. O delineamento experimental utilizado foi o completamente casualizado em um esquema fatorial 2 × 2 × 3 com 3 repetições. A propagação do maracujazeiro amarelo por miniestacas herbáceas foi viável e a manutenção de meia folha no ápice da estaca permitiu a produção de maior número e massa seca de raízes. O corte basal da miniestaca favoreceu pouco a emissão de raízes e a técnica adotada de tratamento das miniestacas com a suspensão de raízes não proporcionou benefícios à propagação da planta.

Palavras-chave: Passiflora edulis f, Flavicarpa, estaquia, enraizamento

\begin{abstract}
The objective of this work was to evaluate the effect of the basal cut, leaf presence and the treament with a root suspension in the rooting of herbaceous minicuttings of yellow passion fruit. The experiment was realized in a greenhouse using minicuttings with $8 \mathrm{~cm}$ of lenght and two nodes, collected from yellow passion fruit seedlings. The longitudinal basal cut in the minicuttings was done until the basal node. The leaves were removed or a half of a single leaf was maintained in the apical node. The minicuttings were treated with a root suspension in water in three concentrations $\left(0,100\right.$ e $\left.200 \mathrm{~g} \mathrm{~L}^{-1}\right)$. After 58 days, the rooting percentage, the number of roots and the root dry matter produced per minicutting were determined. The entirely randomized experimental design was used in a factorial esqueme $(2 \times 2 \times 3)$ with three replications. The propagation of the yellow passion fruit by herbaceous minicuttings was viable and the presence of the half of a single leaf in the apical node give a higher production of number and dry matter of roots. The basal cut was only a little favourable to the production of roots and the treatment with a root suspension did not present a benefit to the plant propagation.
\end{abstract}

Key words: Passiflora edulis f, Flavicarpa, cutting, rooting

\footnotetext{
1 Eng. Agrônomo, Dr., Professor Titular do Centro de Ciências Agrárias e Ambientais da Pontifícia Universidade Católica do Paraná, Campus São José dos Pinhais. Bolsista de Produtividade em Pesquisa, nível II, CNPq, São José dos Pinhais, Paraná. Email: ruy.carvalho@pucpr.br

2 Estudante de Agronomia, PUCPR, CCAA.E-mail: ivo.ds@uol.com.br e rudi2002@ig.com.br.

* Autor para correspondência
} 
O processo de regeneração de uma nova planta a partir de um fragmento de uma planta matriz é chamado de estaquia e é um dos principais métodos utilizados na multiplicação de plantas frutíferas. A estaquia herbácea tem-se mostrado viável para algumas frutíferas como o cacaueiro, com 87,04 a $100 \%$ de enraizamento, e a videira que apresentou enraizamento de $90 \%$ das estacas (ROBERTO et al., 2004). Porém para outras espécies, como a nespereira, a estaquia herbácea proporcionou enraizamento médio máximo de apenas $15,42 \%$ (SILVA; PEREIRA, 2004). Mesmo em espécies com difícil rizogênese, como o caquizeiro, as estacas herbáceas têm maior tendência ao enraizamento (BASTOS et al., 2005).

Em espécies frutíferas, a redução do tamanho da estaca também pode ser utilizada com sucesso em associação a outras técnicas. Estacas de pessegueiro com $12 \mathrm{~cm}$ apresentaram potencial de enraizamento que foi estimulado pelo uso do AIB (DUTRA; KERSTEN; FACHINELLO, 2002) e o corte ou ferimento na base da estaca de pessegueiro também foi benéfico para o enraizamento (TOFANELLI; RODRIGUES; ONO, 2005).

A redução do tamanho da estaca otimiza a utilização da planta matriz, aumentando o número de estacas obtidas em cada coleta. Porém, a obtenção e o manejo da planta matriz podem interferir na qualidade da estaquia. As estacas obtidas de plantas matrizes a campo em condições naturais podem ser chamadas de macroestacas que, ao serem enraizadas e mantidas em casa de vegetação, passam a produzir novas brotações a partir das quais se pode fazer nova estaquia. A permanência de macroestacas enraizadas em casa de vegetação como fornecedoras de ramos rejuvenescidos para estaquia gera um jardim miniclonal do qual podem ser retiradas miniestacas, como já vem sendo utilizado na produção de mudas de Eucalyptus spp. (FERREIRA et al., 2004). O uso de brotações de macroestacas para obtenção de miniestacas foi realizado para a nespereira, porém sem resultados satisfatórios (SILVA; PEREIRA, 2004).
A formação de raízes em estacas ocorre a partir de modificações morfológicas e fisiológicas dos tecidos. O início do processo ocorre pela desdiferenciação de algumas células adultas que retornam à atividade meristemática e originam um novo ponto de crescimento que pode diferenciar células em primórdios de raízes que crescem conectados com um novo sistema vascular e rompem o córtex e a epiderme da estaca. Em estacas herbáceas as raízes podem surgir entre os feixes vasculares e emergir em filas, acompanhando-os, e as folhas na estaca podem favorecer o enraizamento pois são locais de síntese de auxinas que serão translocadas para a base da estaca (FACHINELLO et al., 2005). Mas nem sempre este processo é simples e rápido, pois a desdiferenciação e diferenciação celular podem ser influenciadas por diversos fatores endógenos. Assim, partiu-se da hipótese que se células de raízes ou fragmentos de tecidos de raízes forem colocados em contato com os tecidos internos da estaca por meio de imersão em uma suspensão de raízes da mesma espécie, então os processos iniciais de rizogênese, altamente influenciados pelos fitohormônios, poderiam ser desnecessários uma vez que células já diferenciadas estariam sendo utilizadas bastando que houvesse uma união entre os tecidos radiculares e caulinares. Para tanto é fundamental a coleta de estacas jovens em atividade nas quais a divisão celular é favorecida e a possível união dos tecidos é acelerada. Da mesma forma, quanto maior a área exposta dos tecidos à suspensão de raízes, maior seria a probabilidade de união.

O objetivo deste trabalho foi avaliar a influência do corte basal, da presença da folha e do tratamento com suspensão de raízes no enraizamento de miniestacas herbáceas de maracujazeiro amarelo.

A implantação do experimento ocorreu em abril de 2006 em casa de vegetação com irrigação e ventilação automáticas da Pontifícia Universidade Católica do Paraná, Campus São José dos Pinhais. Foram utilizadas miniestacas herbáceas com $8 \mathrm{~cm}$ de comprimento e dois nós íntegros, obtidas de mudas de maracujazeiro amarelo com haste única de até 
um metro formadas a partir de sementes. Foram utilizadas 50 plantas matrizes para obtenção das miniestacas e cada parcela foi formada por miniestacas provenientes de mudas distintas.

Os tratamentos estudados foram a execução de corte na base das estacas, a manutenção de folhas e o tratamento da base das estacas com suspensão de raízes provenientes de mudas do próprio maracujazeiro obtidas por sementes.

O corte longitudinal na base das estacas foi feito com canivete até a proximidade do nó basal (aproximadamente $2 \mathrm{~cm}$ ). Nas estacas, foram retiradas as folhas ou mantida a folha do nó apical cortada ao meio, transversalmente. As miniestacas foram tratadas com uma suspensão de raízes mais água deionizada nas concentrações de 0,100 e 200 g de raízes para um litro de água.

Para a elaboração da suspensão, as raízes foram retiradas das mudas utilizadas para obtenção das miniestacas, lavadas em água corrente e submetidas ao turbilhonamento em liquidificador por cinco segundos com água deionizada. As miniestacas tiveram suas bases imersas na suspensão de raízes mais água, imediatamente após seu preparo, durante dois minutos.

Após o tratamento, as miniestacas foram acondicionadas em vasos plásticos contendo substrato (Rendmaxâ Floreira) enterrando-se a metade de seu comprimento, mantendo-se 10 miniestacas por vaso. A coleta de dados ocorreu aos
58 dias após a instalação, efetuando-se a determinação da porcentagem de estacas enraizadas, com calo, dormentes e mortas, número de raízes emitidas por estaca e massa de raízes seca em estufa a temperatura de $60^{\circ} \mathrm{C}$ por 96 horas.

$\mathrm{O}$ delineamento experimental utilizado foi o completamente casualizado em um esquema fatorial $2 \times 2 \times 3$ representados pelos tratamentos com ou sem corte basal, com ou sem folhas e pelas três concentrações de suspensão de raízes. Foram utilizados 12 tratamentos e 3 repetições com 10 miniestacas por parcela, totalizando 360 estacas. As médias com diferença significativa pelo teste $\mathrm{F}$ da análise de variância foram submetidas ao teste de Tukey ao nível de significância de $5 \%$ para os fatores com ou sem folhas e com ou sem corte basal e à análise de regressão para o fator dose de suspensão de raízes.

As miniestacas de maracujazeiro amarelo apresentaram enraizamento médio variando de 96,7 a $100 \%$ demonstrando que a técnica da miniestaquia é viável para a espécie (Tabela 1). Ao final do experimento, apenas duas miniestacas estavam mortas, uma permaneceu dormente e em outra houve formação de calo, principalmente quando não havia folha na estaca, e todas as miniestacas que brotaram também enraizaram. Oliveira et al. (2002) obtiveram na estaquia convencional de maracujazeiro amarelo enraizamento variando de 20,7 a 74,0 \% com uso de diferentes substratos. Salomão et al. (2002) obtiveram enraizamento médio de $69 \%$ em estacas herbáceas de maracujazeiro com 10 a $15 \mathrm{~cm}$.

Tabela 1. Dados médios de percentual de enraizamento de miniestacas de maracujazeiro amarelo em função da presença da folha e do corte basal na miniestaca.

Enraizamento $(\%)^{*}$

Presença da folha

Corte basal na miniestaca

Sem corte Com corte

\begin{tabular}{lrrr}
\hline Sem folha & 100,0 Aa & 96,7 & $\mathrm{Bb}$ \\
Com folha & 98,9 & $\mathrm{Aa}$ & 100,0 Aa \\
$\mathrm{CV}=2,92 \%$ & & &
\end{tabular}

*Médias seguidas por letras distintas, maiúsculas nas colunas e minúsculas nas linhas, diferem entre si pelo teste de Tukey ao nível de significância de $5 \%$.

Semina: Ciências Agrárias, Londrina, v. 28, n. 3, p. 387-392, jul./set. 2007 
Mesmo com alto percentual de enraizamento, os tratamentos aplicados às miniestacas interferiram nas médias finais obtidas, em especial quando foi estudada a interação entre os fatores presença de folhas e corte basal na estaca. Quando não se fez o corte basal na estaca, a folha não foi necessária para a promoção do enraizamento, atingindo 100,0 \% de miniestacas enraizadas. Porém, quando se fez o corte basal, a manutenção da folha favoreceu significativamente o enraizamento, obtendo-se todas as estacas enraizadas (Tabela 1). O corte basal em estacas lenhosas representa uma lesão que favorece a divisão celular estimulada pelo aumento na taxa respiratória e nos teores de auxina, carboidratos e etileno na área lesionada (FACHINELLO et al., 2005). Em estacas herbáceas em atividade, há necessidade de maior velocidade de cicatrização dos tecidos lesionados e as folhas têm o papel importante de favorecer o fluxo de reservas à região lesionada e retomar o crescimento $\mathrm{O}$ tratamento com a suspensão de raízes não interferiu na porcentagem final de miniestacas enraizadas.

Houve interferência isolada da presença da folha e do corte basal no número de raízes emitidas por miniestaca. Mantendo-se a metade da folha superior na miniestaca o número médio de raízes emitidas aumentou de 13,21 para 19,51, representando um acréscimo de 47,7 \% (Tabela 2). Estes valores encontrados podem ser considerados elevados pois Salomão et al. (2002) obtiveram de 11 a 13 raízes por estaca de maracujazeiro amarelo com 10 a 15 $\mathrm{cm}$ coletadas a campo. Mesmo nas miniestacas de maracujazeiro sem folhas o número de raízes formado foi superior ao encontrado em estacas herbáceas de outras espécies como a videira (4,4 a 11,17 raízes por estaca) (ROBERTO et al., 2004). Em estacas herbáceas de difícil enraizamento, o número médio de raízes emitidas por estaca foi de, no máximo, 1,52 para a nespereira (SILVA; PEREIRA, 2004) e 2,22 para o caquizeiro (BASTOS et al., 2005). Em estacas herbáceas de cacaueiro, apesar de apresentarem enraizamento de até $100 \%$, o número médio de raízes por estaca atingiu o máximo de 8,97 (FARIA; SACRAMENTO, 2003). Estacas herbáceas de Citrus wolkameriana também apresentaram enraizamento razoável de $65,86 \%$, mas o número médio de raízes obtidas foi de apenas 5,19 (ANDRADE; MARTINS, 2003). Estacas de pessegueiro também apresentaram baixo número de raízes emitidas nas diversas épocas do ano, mas o uso do AIB estimulou a formação de até mais de 100 raízes por estaca (DUTRA; KERSTEN; FACHINELLO, 2002).

O corte basal da miniestaca promoveu menor influência no número de raízes emitidas, passando de 15,43 para 17,29, o que representa acréscimo de $12,1 \%$ (Tabela 2). Tofanelli, Rodrigues e Ono (2005) citaram que o corte lateral e da casca na base das estacas de pessegueiro favoreceram o enraizamento de estacas semilenhosas. As lesões na base das estacas permitem que haja rompimento de uma possível barreira física formada por anéis de esclerênquima, que podem impedir a emergência das raízes. Porém nas miniestacas herbáceas de maracujazeiro não há estas barreiras comuns em estacas mais lignificadas, fato que diminui o efeito benéfico do corte basal. Como esta técnica é trabalhosa, considera-se que sua execução não trouxe benefícios práticos à miniestaquia do maracujazeiro.

Tabela 2. Dados médios do número de raízes emitidas por miniestacas de maracujazeiro amarelo em função da presença da folha e do corte basal na miniestaca.

\begin{tabular}{lc}
\hline Tratamento & Número de raízes por miniestaca* \\
\hline Sem folhas & $13,21 \quad \mathrm{~B}$ \\
Com folhas & $19,51 \quad \mathrm{~A}$ \\
Sem corte basal & $15,43 \quad \mathrm{~B}$ \\
Com corte basal & $17,29 \mathrm{~A}$ \\
$\mathrm{CV}=16,12 \%$ & \\
\hline
\end{tabular}

*Médias seguidas por letras distintas diferem entre si pelo teste de Tukey ao nível de significância de $5 \%$. 
O tratamento com a suspensão de raízes não proporcionou efeito benéfico esperado. $\mathrm{O}$ tratamento com a suspensão de raízes não interferiu no número de raízes emitidas pelas miniestacas independentemente do corte basal e da presença da folha.

A produção de massa seca de raízes não foi influenciada pelo corte basal da miniestaca mas foi estimulada pela presença da folha, elevando a massa produzida de 33,19 para 50,64 $\mathrm{mg}_{\text {estaca-1, }}$, representando aumento de 52,6\%. Em relação à estaquia convencional do maracujazeiro amarelo, estes resultados foram superiores aos encontrados por Salomão et al. (2002) que obtiveram massa seca de raízes de 24,3 $\mathrm{mg} \mathrm{estaca}^{-1}$, mas foram inferiores aos resultados de Oliveira et al. (2002) que encontraram valores variando de 80 a $473 \mathrm{mg}$ estaca $^{-1}$. Estacas de maracujazeiro doce ( $P$. alata) produziram massa seca média de 109,3 $\mathrm{mg}$ estaca $^{-1}$ (SALOMÃO et al., 2002) e em estacas de cacaueiro houve produção de

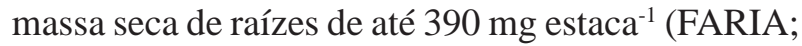
SACRAMENTO, 2003). Estacas de pessegueiro com $12 \mathrm{~cm}$ de comprimento produziram no verão massa seca de raízes de até $126 \mathrm{mg} \mathrm{estaca}^{-1}$ e na primavera até próximo a $600 \mathrm{mg}^{- \text {estaca }^{-1}}$ (DUTRA; KERSTEN; FACHINELLO, 2002) enquanto estacas herbáceas de videira produziram massa seca de raízes de até $120 \mathrm{mg}$ estaca $^{-1}$ (ROBERTO et al., 2004). Para outras espécies de interesse agrícola, a massa seca de raízes produzida por estaca variou de 22,7 mg para a Pfaffia glomerata (NICOLOSO; CASSOL; FORTUNATO, 2001) até mais de 1000 mg estaca ${ }^{-1}$ para a Lippia alba (BIASI; COSTA, 2003). Mas há casos em que a produção de massa seca de raízes chega a ultrapassar $4000 \mathrm{mg} \mathrm{estaca}^{-1}$ como para a Mikania laevigata que apresenta fácil enraizamento (LIMA et al., 2003). Como miniestacas herbáceas têm menos reservas nos tecidos, pode-se considerar razoável a massa de raízes produzida pelas miniestacas do maracujazeiro.

O tratamento com a suspensão de raízes interferiu favoravelmente na massa seca de raízes emitidas quando foi utilizada a dose de $100 \mathrm{~g} \mathrm{~L}^{-1}$. Por interpolação de dados na curva de regressão (Y = $0,00089 \mathrm{x}^{2}+0,183 \mathrm{x}+38,42$ ) o uso de $103 \mathrm{~g} \mathrm{~L}^{-1}$ seria mais favorável à produção de massa seca, porém a massa obtida não foi superior à encontrada nas estacas com folhas, sugerindo que a manutenção da folha foi mais eficiente que o tratamento com a suspensão de raízes e não houve efeito sinérgico entre as duas técnicas. $\mathrm{O}$ uso de $200 \mathrm{~g} \mathrm{~L}^{-1}$ não promoveu benefícios em relação à testemunha talvez pela elevada concentração de fragmentos de raízes na suspensão que prejudicou o tratamento da estaca reduzindo a possibilidade de penetração de algum fragmento no corte efetuado. Contrariando a hipótese que o contato entre fragmentos de raízes e os tecidos jovens internos das miniestacas aumentaria quantitativamente o percentual de estacas enraizadas e o número de raízes emitidas, verificou-se que o uso da suspensão de raízes aumentou a qualidade do enraizamento, obtendo-se mudas com maior valor de massa de raízes, o que favorecerá o pegamento e o crescimento da muda no campo.

Conclui-se que a manutenção de meia folha no ápice da estaca permite a produção de maior número e massa seca de raízes em miniestacas herbáceas de maracujazeiro amarelo. O corte basal da miniestaca favorece pouco a emissão de raízes e a técnica adotada de tratamento das miniestacas com a suspensão de raízes não proporcionou benefícios à propagação da planta.

\section{Referências}

ANDRADE, R. A.; MARTINS, A. B. G. Propagação vegetativa de porta-enxertos para citros. Revista Brasileira de Fruticultura, Jaboticabal, v.25, n.1, p.134136, 2003.

BASTOS, D. C.; PIO, F.; SCARPARE FILHO, J. A.; LIBARDI, M. N.; ALMEIDA, L. F.P.; ENTELMANN, F. A. Enraizamento de estacas lenhosas e herbáceas de cultivares de caquizeiro com diferentes concentrações de ácido indolbutírico. Revista Brasileira de Fruticultura, Jaboticabal, v.27, n.1, p.182-184, 2005.

BIASI, L. A.; COSTA, G. Propagação vegetativa de Lippia alba. Ciência Rural, Santa Maria, v.33, n.3, p.455-459, 2003. 
DUTRA, L. F.; KERSTEN, E.; FACHINELLO, J. C. Época de coleta, ácido indolbutírico e triptofano no enraizamento de estacas de pessegueiro. Scientia Agricola, Piracicaba, v.59, n.2, p.327-333, 2002.

FACHINELLO, J. C.; HOFFMANN, A.; NACHTIGAL, J. C.; KERSTEN, E. Propagação vegetativa por estaquia. In: FACHINELLO, J. C.; HOFFMANN, A.; NACHTIGAL, J. C. Propagação de plantas frutíferas. Brasília: Embrapa Informação Tecnológica, 2005. p.69-109.

FARIA, J. C.; SACRAMENTO, C. K. Enraizamento e crescimento de estacas herbáceas do cacaueiro (clones CEPEC 42, TSH 516 e TSH 1188) em função da aplicação do ácido indolbutírico (AIB). Revista Brasileira de Fruticultura, Jaboticabal, v.25, n.1, p.192-194, 2003.

FERREIRA, E. M.; ALFENAS, A. C.; MAFIA, R. G.; LEITE, H. G.; SARTORIO, R. C.; PENCHEL FILHO, R. M. Determinação do tempo ótimo do enraizamento de miniestacas de clones de Eucalyptus spp. Revista Árvore, Viçosa, v.28, n.2, p.183-187, 2004.

LIMA, N. P.; BIASI, L. A.; ZANETTE, F.; NAKASHIMA, T. Produção de mudas por estaquia de duas espécies de guaco. Horticultura Brasileira, Brasília, v.21, n.1, p.106109, 2003.

NICOLOSO, F. T.; CASSOL, L. F.; FORTUNATO, R. P. Comprimento da estaca de ramo no enraizamento de ginseng brasileiro (Pfaffia glomerata). Ciência Rural, Santa Maria, v.31, n.1, p.57-60, 2001.
OLIVEIRA, J. A.; JUNQUEIRA, N. T. V.; PEIXOTO, J. R.; PEREIRA, A. V. Efeito dos substratos artificiais no enraizamento e no desenvolvimento de estacas de maracujazeiro-azedo (P. edulis Sims f. flavicarpa Deg.). Revista Brasileira de Fruticultura, Jaboticabal, v.24, n.2, p.505-508, 2002.

ROBERTO, S. R.; PEREIRA, F. M.; NEVES, C. S. V. J.; JUBILEU, B. S.; AZEVEDO, M. C. B. Enraizamento de estacas herbáceas dos porta-enxertos de videira 'Campinas' (IAC 766) e 'Jales' (IAC) 572 em diferentes substratos. Ciência Rural, Santa Maria, v.34, n.5, p.16331636, 2004.

SALOMÃO, L. C.C.; PEREIRA, W.E.; DUARTE, R. C.C.; SIQUEIRA, D. L. Propagação por estaquia dos maracujazeiros doce (Passiflora alata Dryand.) e amarelo (P. edulis f. flavicarpa O. Deg.). Revista Brasileira de Fruticultura, Jaboticabal, v.24, n.1, p.163-167, 2002.

SILVA, J. A. A.; PEREIRA, F. M. Enraizamento de estacas herbáceas de nespereira (Eriobotrya japonica Lindl.). Revista Brasileira de Fruticultura, Jaboticabal, v.26, n.2, p.369-371, 2004.

TOFANELLI, M. B. D.; RODRIGUES, J. D.; ONO, E. O. 2,6di-hidroxiacetofenona e tipo de corte basal no enraizamento de estacas semi-lenhosas de pessegueiro 'Okinawa'. Ciência Rural, Santa Maria, v.35, n.2, p.462464, 2005. 